\title{
The interplay between finance and actuarial science
}

Recently, many products sold by insurance companies are mutual funds, wrapped with some insurance features or guarantees. These guarantees and the embedded options should be priced, hedged and reserved using modern option pricing theory. On the other hand, banks and financial firms are selling products with insurance features nowadays. This new development makes the interplay between finance and actuarial science an important and interesting research area. In this special issue of Risk and Decision Analysis on Insurance and Finance, we selected 8 papers which are on actuarial science and finance or the interplay of these two subjects. We hope that these selected papers will provide insights on the risk management of insurance and financial portfolios.

The topics of the selected papers in this special issue are all related to risk management of insurance and/or financial portfolios. The paper "Insolvencies in the American property and casualty insurance industry: A systems' approach" by Léa A. Deleris and M. Elisabeth Paté-Cornell investigates insolvencies in the American property and casualty insurance industry by using the engineering risk analysis approach. This research suggests that the current practice of adapting pricing to market conditions (soft or hard markets) may in fact be sensible in terms of insolvency risk. The paper shows that while small companies are associated with higher insolvency risk, the effect of size is noticeable either for very small firms or for firms who do not adjust their sales level to their surplus value. The paper "Insurance and finance: Competition and/or convergence" by Charles S. Tapiero discusses facets of the insurance-finance convergence and their competition, and some questions relating to the efficiency of portfolio securitization are also raised in light of the latent and macroeconomic risks that have pervaded insurance and financial insurance portfolios during the financial crisis. The paper "A mixed Sharpe ratio" by W.K. Wong, J.A. Wright, S.C.P. Yam and S.P. Yung constructs a mixed Sharpe ratio (they called it a reward- to-variability ratio). The paper investigates the optimal portfolio strategy using this ratio. The paper also compares the performances of the 'bang-bang' and 'buyand-hold' trading strategies. The paper "An overview of conditional comonotonicity and its applications" by Ka Chun Cheung summarizes some recent research results of an important and useful concept in actuarial science: comonotonicity. The conditional version of this concept has some very interesting applications in both actuarial science and finance. CDO is a derivative product which combines insurance and financial innovations. The paper "CDO: A modeling prospective" by Tapiero and Totouom-Tangho discusses CDOs in details from a modeling point of view. Asset liability management is one of the most important problems in insurance and financial industries. The paper "Viabilist and tychastic approaches to guaranteed ALM problem" by Aubin et al. proposes using the tools of viabilist and tychastic to deal with the ALM. The paper "On proportional reinsurance with a linear transaction rate" by Luo studies an insurance risk model with investment and reinsurance. The optimal reinsuranceinvestment problem is solved using stochastic control approach when there is transaction cost. The paper "Elasticity approach to asset allocation in discrete time" considers a portfolio consisting an option, the underlying stock and a risk free asset, and applies the elasticity approach to optimal asset allocation problems in discrete time setting. The optimal strategy and properties of the optimal strategy are discussed.

The papers selected in this special issue were either presented or inspired by the International Research Forum held at the Hong Kong Polytechnic University in December 2010.

Hailiang Yang

Department of Statistics and Actuarial Science The University of Hong Kong Hong Kong 